\title{
Experimental investigation and constitutive model for lime mudstone
}

\author{
Junbao Wang ${ }^{1,2^{*}} \mathbb{1}$, Xinrong Liu ${ }^{1,2+}$, Baoyun Zhao ${ }^{3 \dagger}$, Zhanping Song ${ }^{1}$ and Jinxing Lai ${ }^{4}$
}

${ }^{*}$ Correspondence:
xajdwangjunbao@163.com
${ }^{\dagger}$ Xinrong Liu and Baoyun
Zhao contributed equally
to this work and should be
considered as co-first authors
${ }^{1}$ School of Civil
Engineering, Xi'an
University of Architecture
and Technology,
Xi'an 710055, China
Full list of author information
is available at the end of the
article

${ }^{*}$ Correspondence:

xajdwangjunbao@163.com

Zhao contributed equally

to this work and should be

considered as co-first authors

School of Civil

University of Architecture

and Technology,

Full list of author information

article

\begin{abstract}
In order to investigate the mechanical properties of lime mudstone, conventional triaxial compression tests under different confining pressures $(0,5,15$ and $20 \mathrm{MPa})$ are performed on lime mudstone samples. The test results show that, from the overall perspective of variation law, the axial peak stress, axial peak strain and elastic modulus of lime mudstone tend to gradually increase with increasing confining pressure. In the range of tested confining pressure, the variations in axial peak stress and elastic modulus with confining pressure can be described with linear functions; while the variation in axial peak strain with confining pressure can be reflected with a power function. To describe the axial stress-strain behavior in failure process of lime mudstone, a new constitutive model is proposed, with the model characteristics analyzed and the parameter determination method put forward. Compared with Wang' model, only one parameter $n$ is added to the new model. The comparison of predicted curves from the model and test data indicates that the new model can preferably simulate the strain softening property of lime mudstone and the axial stress-strain response in rock failure process.
\end{abstract}

Keywords: Lime mudstone, Mechanical property, Test, Constitutive model

\section{Background}

With the development of economy, a large number of rock projects are emerging. To guarantee the safety of these projects, it is very important to study the mechanical properties of rock (Singh, et al. 2015; Nadimi et al. 2011; Wang et al. 2014; Yang et al. 2015; Nadimi and Shahriar 2014; Chen et al. 2016a, b; Lai et al. 2016), which as a kind of natural geological material contains many flaws (for instance, joints, micro cracks, faults, etc.). The existence of these flaws complicates the mechanical behavior of rock.

In the past decades, many efforts have been directed toward the study on mechanical properties of rock. Among them, experimental investigation and constitutive relation are two important aspects. Taking experimental study on mechanical properties of rock as an example, Chen et al. (2016a, b) conducted a series of conventional triaxial compression tests on granite to investigate the pre-failure damage and found that the damage increases slowly before the reversal of volumetric strain and accelerates quickly afterwards. Xia and Zhou (2010) studied the failure process of brittle rock under uniaxial and triaxial compression. The results revealed that rock failure is caused by axial splitting under uniaxial compression; as the confining pressure increases, rock failure occurs

(c) 2016 The Author(s). This article is distributed under the terms of the Creative Commons Attribution 4.0 International License (http://creativecommons.org/licenses/by/4.0/), which permits unrestricted use, distribution, and reproduction in any medium, provided you give appropriate credit to the original author(s) and the source, provide a link to the Creative Commons license, and indicate if changes were made. 
in a few localized shear planes and the rock mechanical behavior is changed from brittle to ductile. To study the mechanical strength and deformation of sandstone, Zhang et al. (2015a, b) performed a series of mechanical tests on sandstone samples. They showed that there is a clear transition from volumetric compressibility to dilatancy and a strong dependency on confining pressure. Yang et al. (2012) carried out conventional triaxial compression and "reducing confining pressure" experiments on red sandstone. The test results showed that the post-peak axial deformation characteristics of red sandstone change as the confining pressure are increased from 5 to $65 \mathrm{MPa}$ and Young's modulus of red sandstone increases nonlinearly with increasing confining pressure. Kahraman and Alber (2008) investigated the uniaxial and triaxial strength of a fault breccia. They found that the uniaxial and triaxial strength of such heterogeneous rocks as fault breccia varies with the proportion of blocks in the sample, the relative strength of the blocks and host matrix and the size of the tested specimen. Hu et al. (2014) tested the mechanical and poromechanical behavior of claystone. The results indicated that the pore pressure, under low confining stress, undergoes a transition from increase to decrease due to the evolution of volumetric strain from contraction to dilatation and this transition gradually disappears under high confining stress. In order to investigate deep reservoir rock properties in High Pressure and High Temperature environments, triaxial tests were performed on Carthage marble and Crab Orchard sandstone samples by Zhang et al. (2015a, b). It was found that with the increase of confining pressure, the Carthage marble changes from strain-softening to strain-hardening, and the Crab Orchard sandstone exhibits brittle or strain-softening behavior; at high temperature, tensile cracks and axial splitting are observed on both rocks; strength of the two rock types is directly dependent on confining pressure and inversely related to temperature. Also, the influence of loading path (Yang et al. 2011; Lee et al. 1999), preexisting flaws (Huang et al. 2015; Yu et al. 2015) and stress state factor (Alexeev et al. 2008) on rock mechanical properties are studied.

For the study on constitutive relation of rock, Taheri and Tani (2013) carried out two series of multiple-step loading triaxial compression tests on a sedimentary soft rock of mudstone. Furthermore, they proposed a multiple-step loading damage model to simulate multiple-step loading triaxial compression test results. The first series was to determine the geotechnical parameters to describe the multiple-step loading damage model, and the second series was to verify the model. The results demonstrated that the proposed multiple-step loading damage model is powerful in simulating multiplestep loading triaxial compression tests on the mudstone. Indraratna et al. (2014) developed a multiphase constitutive model using a critical state framework which includes a kinematic yield locus and a modified stress-dilatancy approach. This model is able to quantify the role of fouling on the permanent strains of the fouled ballast. On the basis of a combination of plasticity theory and the theory of damage mechanics along the lines of a damage-plastic model, Unteregger et al. (2015) presented a constitutive model to describe the nonlinear mechanical behavior of different types of intact rock. The model was validated by numerical simulations of laboratory experiments conducted on specimens of marble, granite and sandstone. Asadollahi et al. (2010) modified the Barton's empirical model for rock fractures in order to address its limitations and validated it by conducting a series of direct shear tests. Siddiquee et al. (2013) developed a 
phenomenological model for soft rock based on the results of a series of triaxial compression tests conducted on Kobe sandstone with a very high precision measurement. They simulated the plate loading test results successfully using this model. To characterize the mechanical behavior of rock materials under high confining pressures and high strain rates, a dynamic material model was established by Li and Shi (2016). The reliability and accuracy of the model were verified by the simulation of various basic experiments under different loading conditions. The results indicated that this model is capable of capturing the failure of rock materials. To describe rock mechanical behaviors, Deng and Gu (2011), Liu and Zhang (2015), Li et al. (2015a, b) and Wang et al. (2007) constructed statistical damage constitutive models by taking different strength criteria as a random distributed variable of rock mesoscopic element strength, respectively.

In order to better understand the mechanical properties of lime mudstone, conventional triaxial compression tests under different confining pressures are performed on cylindrical lime mudstone samples. Based on the analyses on test results, a new constitutive model is proposed to simulate the axial stress-strain behavior of lime mudstone in this study.

\section{Experimental investigation} Materials and test equipment

Lime mudstone samples used in the tests were obtained from the roof stratum of a salt mine in Huai'an, Jiangsu, China. The salt unit is considered as a host rock for underground gas storage. To analyze the stability of the gas storage, it is very important to study the mechanical behavior of the roof stratum. The lime mudstone samples, drilled from depths ranging between 1600 and $1700 \mathrm{~m}$, were processed into cylinders with a diameter of $50 \mathrm{~mm}$ and a height of $100 \mathrm{~mm}$, according to the International Society for Rock Mechanics (Fairhurst and Hudson 1999). The average bulk density of the samples is about $2.56 \mathrm{~g} / \mathrm{cm}^{3}$, and the colors of them are grey and dark grey.

All tests were carried out in an MTS 815 rock material testing system. This machine is mainly used to test the mechanical properties of solid material under complex stress state. It is suitable for tension, uniaxial compression, triaxial compression, creep, relaxation, and cyclic loading tests for rocks. The maximum axial load is $2800 \mathrm{kN}$, and the maximum confining pressure is $80 \mathrm{MPa}$.

\section{Test procedure}

To obtain the stress-strain curves of lime mudstone under different confining pressures, four samples (\#1, \#2, \#3 and \#4) were chosen to perform the conventional triaxial compression tests under different confining pressures $\left(\sigma_{3}\right)$ of $0(\# 1), 5(\# 2), 15(\# 3)$ and $20 \mathrm{MPa}(\# 4)$. The following four steps are contained in the test procedure. First, the sample to be tested was covered with a rubber sleeve to make it oil-proof. Second, the covered sample was installed in triaxial pressure cell. Third, the confining pressure was applied at a constant rate of $0.1 \mathrm{MPa} / \mathrm{s}$ till it reached the desired value. Finally, the axial stress was applied at a constant axial displacement rate of $0.1 \mathrm{~mm} / \mathrm{min}$ until rock failure. 


\section{Results and analyses}

\section{Deformation behavior}

Figure 1 shows the axial stress-strain curves of the lime mudstone samples under different confining pressures. It can be seen from Fig. 1 that all of the four samples show their strain softening behaviors under different confining pressures, and the rock strength constantly increases with increasing confining pressure.

The deformation behavior of lime mudstone is elaborated with sample \#2 $\left(\sigma_{3}=5 \mathrm{MPa}\right)$. According to Fig. 1 , the axial stress-strain curve of this sample can be divided into four stages (Huang et al. 2015; Liang et al. 2011). (a) Stage I: closure of voids and cracks (before point A). The action of the confining pressure and axial stress gradually closes the open micro structural planes and the micro cracks intrinsically inside the lime mudstone sample and the sample is compacted, which hardens and improves the mechanical properties of rock. At the macro level, the axial stress-strain curve gradually bends to the vertical axis (stress axis) with the increase of strain. (b) Stage II: elastic deformation (the segment between point A and B). At this stage, the deformation of lime mudstone shows linear regular growth with increasing stress, and its axial stress-strain curve is approximate to a straight line. (c) Stage III: plastic deformation (the segment between point $\mathrm{B}$ and $\mathrm{C}$ ). With the further increase of axial stress, the pre-existing cracks inside the lime mudstone sample are gradually developing and new cracks are continuously emerging (Huang et al. 2015; Liang et al. 2011). Therefore, the unrecoverable plastic deformation happens to the sample. At the macro level, the axial stress-strain curve gradually deviates from the straight line and bends to the abscissa axis (strain axis) till it reaches the peak stress (point C). (d) Stage IV: strain softening (after point C). Once the axial stress reaches its peak value, the global internal structures of the lime mudstone sample are damaged and its bearing capacity gradually decreases while its deformation increases continuously.

For the discreteness of the four lime mudstone samples used in the tests, only the axial stress-strain curve of sample \#2 $\left(\sigma_{3}=5 \mathrm{MPa}\right)$ covers all the aforesaid four stages and that of the other three samples covers only such three stages as the elastic deformation stage, the plastic deformation stage and the strain softening stage, without obvious closure

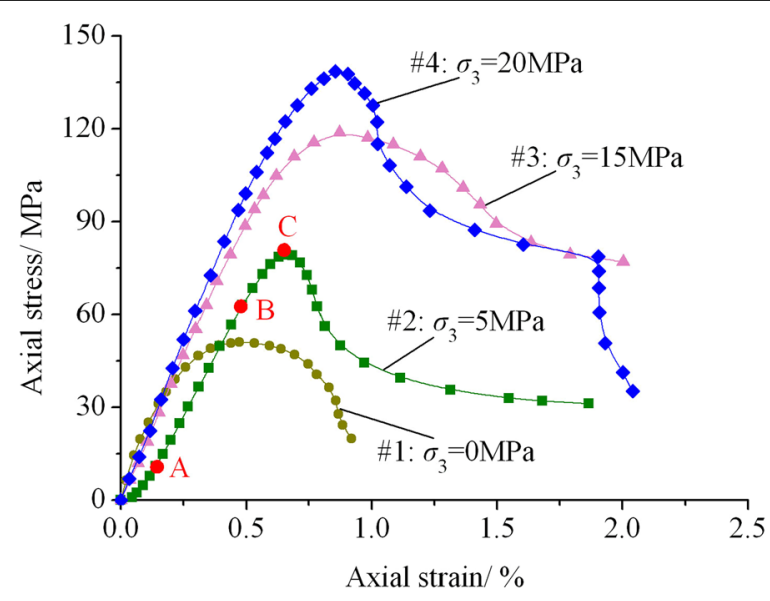

Fig. 1 Axial stress-strain curves of lime mudstone under different confining pressures 
stage of voids and cracks. In addition, sample \#1 $\left(\sigma_{3}=0 \mathrm{MPa}\right)$ has a relatively short elastic deformation stage but its plastic deformation stage before the peak stress is comparatively long. Moreover, from Fig. 1, it is noted that the axial stress-strain curve of sample \#4 $\left(\sigma_{3}=20 \mathrm{MPa}\right)$ has an abrupt stress drop. The possible reason is that once the axial stress applied to the sample reaches its peak value, a macroscopic shear fracture plane will be formed and the complete sample is split into two blocks by the shear fracture plane. Then the damaged sample still has a certain bearing capacity because of the existence of friction force between the two blocks. However, the bearing capacity of the damaged sample decreases gradually with increasing strain. When the strain increases to a certain value, further rock failure happens to one of the two blocks, which results in the abrupt stress drop.

\section{Influence of confining pressure on axial peak stress}

The stress corresponding to the peak point of stress-strain curve is the axial peak stress $\left(\sigma_{1 \mathrm{c}}\right)$ of rock. Figure 2 shows the variation in axial peak stresses of the four lime mudstone samples with confining pressure. From Fig. 2, it can be seen that the axial peak stress of lime mudstone gradually increases with increasing confining pressure. Many efforts have been devoted to the relationship between rock axial peak stress and confining pressure, with a number of strength criteria proposed. Among them, the linear Mohr-Coulomb strength criterion is extensively used in practical projects (Zhang et al. 2015a, b; Yang et al. 2011; Li et al. 2015a, b) because it has a simple expression and can reflect the essence of shear failure for materials. The linear Mohr-Coulomb strength criterion can be expressed as

$$
\sigma_{1 \mathrm{c}}=k \sigma_{3}+\sigma_{0}
$$

where $\sigma_{1 \mathrm{c}}$ is the axial peak stress, $\sigma_{3}$ is the confining pressure, $\sigma_{0}$ is usually regarded as the uniaxial compression strength of rock sample, and $k$ is a material constant. $\sigma_{0}$ and $k$ are related to the cohesion $c$ and the internal friction angle $\phi$ of rock material, which can be expressed in the following forms, respectively.

$$
k=\frac{1+\sin \varphi}{1-\sin \varphi}
$$

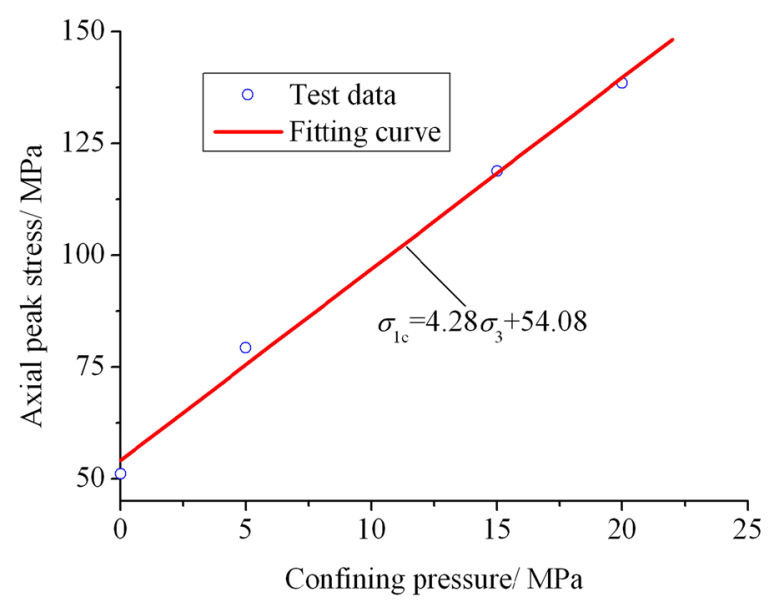

Fig. 2 Variation in axial peak stress with confining pressure 


$$
\sigma_{0}=\frac{2 c \cos \varphi}{1-\sin \varphi}
$$

Fitting analysis is made to the relationship between axial peak stress and confining pressure shown in Fig. 2 using Eq. (1). It can be obtained that

$$
\sigma_{1 \mathrm{c}}=4.28 \sigma_{3}+54.08
$$

The correlation coefficient $R=0.99$. Figure 2 also shows the comparison of fitting curve and test data. It can be seen that the fitting curve is in good agreement with the test data, which indicates that the relationship between axial peak stress of lime mudstone and confining pressure conforms well with the linear Mohr-Coulomb strength criterion in the range of $0 \mathrm{MPa} \leq \sigma_{3} \leq 20 \mathrm{MPa}$. Then substituting $k=4.28$ and $\sigma_{0}=54.08 \mathrm{MPa}$ into Eqs. (2) and (3), the cohesion and internal friction angle of lime mudstone can be determined as $c=13.07 \mathrm{MPa}$ and $\phi=38.41^{\circ}$, respectively.

Here it should be noticed that the uniaxial compressive strength $\left(\sigma_{3}=0 \mathrm{MPa}\right)$ of lime mudstone calculated with Eq. (4) is $54.08 \mathrm{MPa}$, while its actual uniaxial compressive strength is $51.14 \mathrm{MPa}$, lower than the calculated value. That is because the MohrCoulomb strength criterion reflects the essence of material shear failure, but the tensile strength of rock is relatively low and in the circumstance of uniaxial compression, the horizontal tensile stress produced by axial compression inside the sample tends to reach the tensile strength first and thus causes the horizontal tensile failure of rock, not shear failure. Therefore, the actual uniaxial compressive strength of rock is generally lower than that calculated with the Mohr-Coulomb formula.

\section{Influence of confining pressure on axial peak strain}

The strain corresponding to the peak point of stress-strain curve is the axial peak strain $\left(\varepsilon_{1 \mathrm{c}}\right)$ of rock. According to the conventional triaxial compression test results of marble (Yang et al. 2005) and coal (Yang et al. 2006) under different confining pressures, the axial peak strains of marble and coal show linear increase with increasing confining pressure. Our test data indicate that as for the lime mudstone samples \#1, \#2 and \#3, their axial peak strains constantly increase with the increase of confining pressure, while the axial peak strain of sample \#4 is basically identical with that of sample \#3. This is mainly due to the discreteness and heterogeneity of the sample. From the overall perspective of variation law, the axial peak strain of lime mudstone tends to gradually increase with increasing confining pressure. Through fitting analysis, the variation in axial peak strain of lime mudstone with confining pressure may be approximately described with the power function expressed by Eq. (5) and the correlation coefficient $R=0.98$. The comparison of fitting curve and test data is presented in Fig. 3. It can be seen that the fitting curve is in good agreement with the test data.

$$
\varepsilon_{1 \mathrm{c}}=9.28 \times 10^{-4} \sqrt{\sigma_{3}}+4.69 \times 10^{-3}
$$

where $\varepsilon_{1 \mathrm{c}}$ is the axial peak strain. 


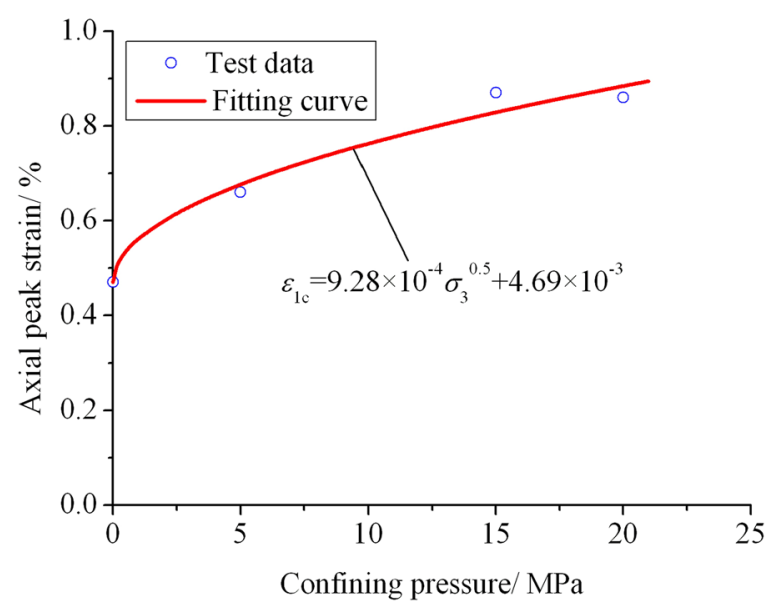

Fig. 3 Variation in axial peak strain with confining pressure

\section{Influence of confining pressure on elastic modulus}

For different types of rocks, the confining pressure has different influence on their elastic modulus. You (2003) pointed out that the elastic modulus of the macroscopically homogeneous and compacted rock sample or that only with local flaws is independent of confining pressure. However, for the sample with joints and cracks, the increased confining pressure may close the joints, cracks, etc., and the friction force between the fissure surfaces may be increased so as to improve the rock elastic modulus.

Here, the elastic modulus of rock is defined as the slope of the axial stress-strain curve at elastic deformation stage (At this stage, the axial stress-strain curve is approximate to a straight line, and its slope remains basically invariable). Then, according to the axial stress-strain curves shown in Fig. 1, the elastic modulus of lime mudstone samples can be determined as 15,751 (\#1), 16,179 (\#2), 18,833 (\#3) and 20,589 MPa (\#4), respectively. Figure 4 illustrates the variation in elastic modulus of the four lime mudstone samples with confining pressure. As shown in Fig. 4, the elastic modulus of lime mudstone gradually increases with the increase of confining pressure, and its variation law may be

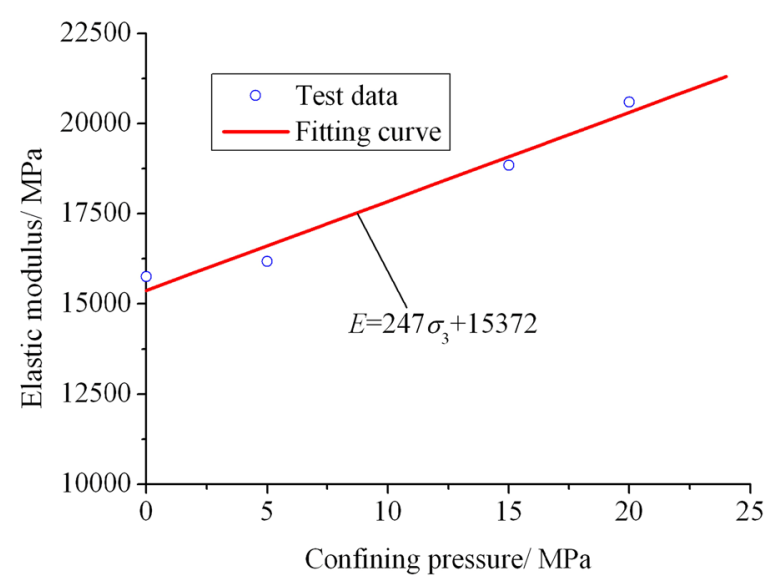

Fig. 4 Variation in elastic modulus with confining pressure 
well fitted with the linear function expressed by Eq. (6) and the correlation coefficient $R=0.98$.

$$
E=247 \sigma_{3}+15372
$$

where $E$ is the elastic modulus.

\section{Influence of confining pressure on failure mode}

The failure modes of lime mudstone samples under uniaxial $\left(\sigma_{3}=0 \mathrm{MPa}\right)$ and triaxial $\left(\sigma_{3}>0 \mathrm{MPa}\right)$ compression are presented in Fig. 5 . It is easy to see that the failure modes of lime mudstone are different under uniaxial and triaxial compression. Under uniaxial compression, the lime mudstone takes on a horizontal tensile splitting failure mode, during which the tensile splitting crack parallel to the axis appears. The reason is that the tensile strength of rock is far lower than its shear strength and the horizontal tensile stress inside the sample produced by the axial compression reaches its tensile strength first. This is different from the failure mode of coarse marble under the condition of uniaxial compression (Yang et al. 2011). Under triaxial compression, the lime mudstone shows a typical shear failure mode, and the shear plane at a certain angle with the horizontal plane is observed. That is because the action of confining pressure is equivalent to improving the horizontal tensile strength of the rock sample and can restrain the appearance and development of the horizontal tensile cracks.

\section{Constitutive model}

\section{Proposal of the model and determination method of parameters}

Duncan and Chang (1970) hyperbola model is widely used in geotechnical engineering because it has a simple expression and is able to reflect the non-linear property of geotechnical materials. However, this model can only simulate the strain hardening behavior of materials. In order to describe the strain softening property of oil sand, Wang et al. (2015) proposed an improved hyperbola model, with its axial stress-strain relation given by

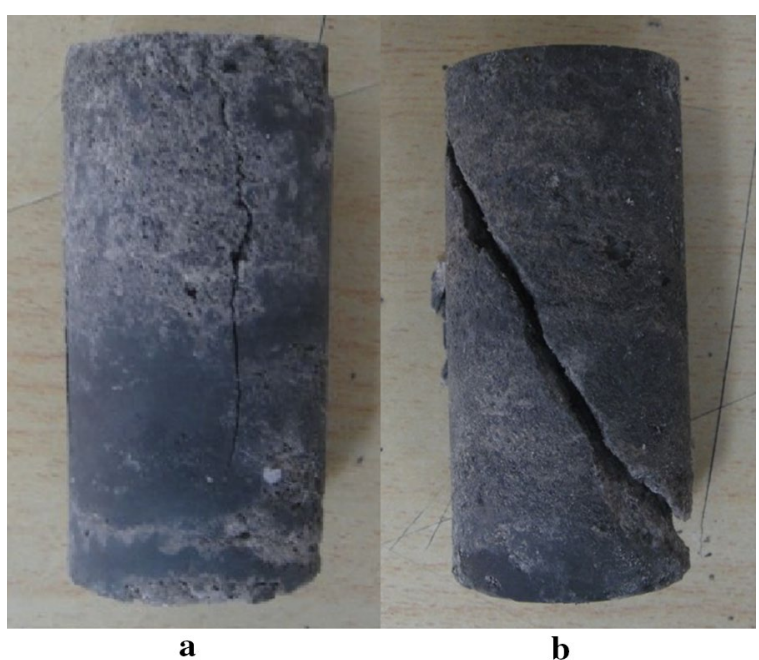

Fig. 5 Failure modes of lime mudstone. a Uniaxial failure. $\mathbf{b}$ Triaxial failure 


$$
\sigma_{1}=\frac{\varepsilon_{1}\left(A \varepsilon_{1}+B\right)}{\varepsilon_{1}^{2}+C}
$$

where $\sigma_{1}$ is the axial stress, $\varepsilon_{1}$ is the axial strain, and $A, B$ and $C$ are material parameters.

The aforesaid model is able to preferably reflect the strain softening property of homogeneous materials, such as oil sand. However, when this model is used to simulate the failure process of lime mudstone, it is found that it has no ideal fitting results in the failure stage (strain softening stage) after the peak point. To precisely simulate the stressstrain response of lime mudstone, a new model with three parameters is proposed. The axial stress-strain relation of this new model is given by

$$
\sigma_{1}=\frac{a \varepsilon_{1}+\varepsilon_{1}^{n}}{1+b \varepsilon_{1}^{n}}
$$

where $a, b$ and $n$ are material parameters and $n \geq 1$.

The characteristics of the model and the parameter determination method are elaborated as follows.

According to Eq. (8), when $\varepsilon_{1} \rightarrow \infty$, the residual strength of rock $\sigma_{\infty}=1 / b$, which indicates that $1 / b$ represents the residual strength of rock.

Taking the derivative with respect to axial strain $\varepsilon_{1}$ in Eq. (8), the expression of the tangent elastic modulus $E_{\mathrm{t}}$ may be obtained to be

$$
E_{\mathrm{t}}=\frac{\mathrm{d} \sigma_{1}}{\mathrm{~d} \varepsilon_{1}}=\frac{a+n \varepsilon_{1}^{n-1}+(1-n) a b \varepsilon_{1}^{n}}{\left(1+b \varepsilon_{1}^{n}\right)^{2}}
$$

It can be seen from Eq. (9) that the initial tangent elastic modulus $E_{0}=a$ when $\varepsilon_{1}=0$. This indicates that parameter $a$ represents the initial tangent elastic modulus of rock. To get better fitting results, parameter $a$ may be replaced with the rock elastic modulus $E$ (the slope of the axial stress-strain curve at the elastic deformation stage).

It is assumed that the axial peak stress of rock is $\sigma_{1 \mathrm{c}}$, the corresponding axial peak strain is $\varepsilon_{1 \mathrm{c}}$. Since the tangent elastic modulus at the peak point of the rock axial stressstrain curve is 0 , i.e., $E_{\mathrm{t}}=0$, according to Eq. (9), it can be obtained

$$
a+n \varepsilon_{1 \mathrm{c}}^{n-1}+(1-n) a b \varepsilon_{1 \mathrm{c}}^{n}=0
$$

Based on Eqs. (10), (11) can be obtained.

$$
b=\frac{1}{(n-1) \varepsilon_{1 \mathrm{c}}^{n}}+\frac{n}{a(n-1) \varepsilon_{1 \mathrm{c}}}
$$

Assuming that the axial stress-strain relation of rock sample may be described with Eq. (8), it can be expressed at the peak point as

$$
\sigma_{1 \mathrm{c}}=\frac{a \varepsilon_{1 \mathrm{c}}+\varepsilon_{1 \mathrm{c}}^{n}}{1+b \varepsilon_{1 \mathrm{c}}^{n}}
$$

Equation (12) can be rewritten as

$$
a \varepsilon_{1 \mathrm{c}}-\sigma_{1 \mathrm{c}}=\left(b \sigma_{1 \mathrm{c}}-1\right) \varepsilon_{1 \mathrm{c}}^{n}
$$


Substituting Eq. (11) into Eq. (13), we get

$$
a \varepsilon_{1 \mathrm{c}}+\varepsilon_{1 \mathrm{c}}^{n}=\frac{n}{n-1} \sigma_{1 \mathrm{c}}\left(1+\frac{\varepsilon_{1 \mathrm{c}}^{n-1}}{a}\right)
$$

According to Eqs. (11) and (14), as long as the axial peak stress $\sigma_{1 \mathrm{c}}$, axial peak strain $\varepsilon_{1 \mathrm{c}}$ and elastic modulus $a(E)$ under a certain confining pressure are given, the model parameters $n$ and $b$ can be determined under this confining pressure. From the analyses on the test results in "Results and analyses" section, it is found that $\sigma_{1 \mathrm{c}}, \varepsilon_{1 \mathrm{c}}$ and $a$ $(E)$ are all dependent on confining pressure $\sigma_{3}$, thus parameters $n$ and $b$ are inevitably dependent on $\sigma_{3}$. To predict the axial stress-strain behavior of lime mudstone under an arbitrary confining pressure, $\sigma_{1 \mathrm{c}}, \varepsilon_{1 \mathrm{c}}$ and $a(E)$ in Eqs. (11) and (14) may be estimated separately with Eqs. (4)-(6). Then substituting Eqs. (4)-(6) into Eq. (14), we have

$$
\begin{aligned}
& \left(247 \sigma_{3}+15372\right)\left(9.28 \times 10^{-4} \sqrt{\sigma_{3}}+4.69 \times 10^{-3}\right)+\left(9.28 \times 10^{-4} \sqrt{\sigma_{3}}+4.69 \times 10^{-3}\right)^{n} \\
& =\frac{n}{n-1}\left(4.28 \sigma_{3}+54.08\right)\left[1+\frac{\left(9.28 \times 10^{-4} \sqrt{\sigma_{3}}+4.69 \times 10^{-3}\right)^{n-1}}{247 \sigma_{3}+15372}\right]
\end{aligned}
$$

Similarly, substituting Eqs. (5) and (6) into Eq. (11), we can obtain

$$
\begin{aligned}
b= & \frac{1}{(n-1)\left(9.28 \times 10^{-4} \sqrt{\sigma_{3}}+4.69 \times 10^{-3}\right)^{n}} \\
& +\frac{n}{\left(247 \sigma_{3}+15372\right)(n-1)\left(9.28 \times 10^{-4} \sqrt{\sigma_{3}}+4.69 \times 10^{-3}\right)}
\end{aligned}
$$

Equations (15) and (16) indicate that parameters $n$ and $b$ are relevant to confining pressure $\sigma_{3}$. For a given confining pressure, parameter $n$ corresponding to this confining pressure may be determined by solving Eq. (15). It should be noticed that Eq. (15) cannot be written to be an explicit form, so it is difficult to solve it directly and its solution $(n)$ may be obtained with iterative method using mathematical software. Then substituting the value of $n$ into Eq. (16), parameter $b$ corresponding to this confining pressure can be determined. Meanwhile, parameter $a(E)$ corresponding to this confining pressure may be estimated with Eq. (6). Thus, according to Eqs. (6), (15) and (16), the model parameters $a(E), b$ and $n$ under an arbitrary confining pressure can be determined. Then the axial stress-strain behavior of lime mudstone under an arbitrary confining pressure can be predicted. This determination method for parameters is conducive to predicting the axial stress-strain response of rock.

\section{Influence of parameter $n$ on the model}

According to the analyses in "Proposal of the model and determination method of parameters" section, parameter $a$ represents the rock elastic modulus, the reciprocal of parameter $b$ represents the residual strength, and parameter $n$ is a fitting parameter, the main function of which is to change the shape of the rock stress-strain curve so as to better fit the test results. In Eq. (8), let $a=2 \times 10^{4} \mathrm{MPa}$ and $b=1 \times 10^{5} \mathrm{MPa}^{-1}$. Figure 6 illustrates the influence of parameter $n$ on the model axial stress-strain curve.

From Fig. 6, it can be observed that the elastic deformation stages of the axial stressstrain curves corresponding to different values of parameter $n$ coincide with each other. 


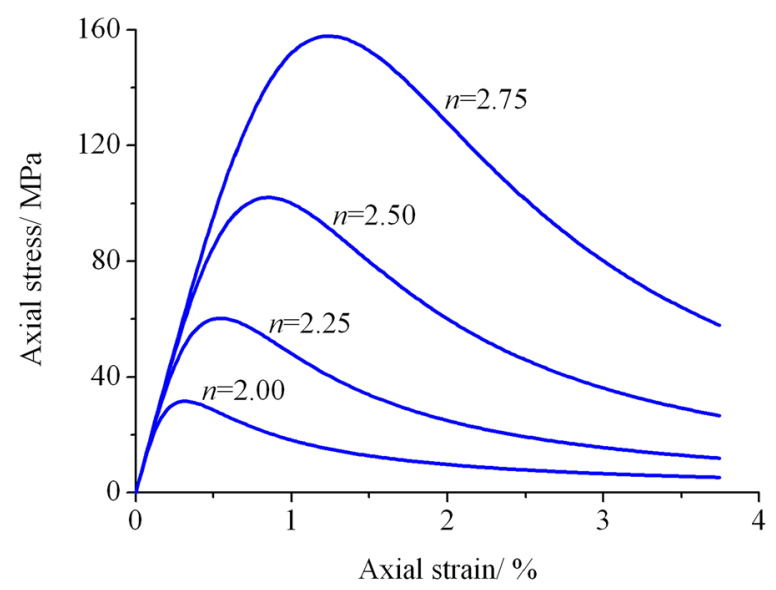

Fig. 6 Influence of parameter $n$ on axial stress-strain curve

As the values of parameter $n$ increase, both the axial peak stress and axial peak strain are constantly increasing; meanwhile, the strain softening property of material is more and more obvious. The model proposed in this paper may degrade into Duncan-Chang model under the condition of $n=1$. Then only the strain hardening property of material can be described and its strain softening behavior cannot be reflected by this model. For different rock samples, the shape of the axial stress-strain curve can be changed by adjusting the value of parameter $n$ so as to better fit the test results. Therefore, the proposed model in this paper has better adaptability in describing the axial stress-strain response of rock material.

\section{Validation of the model}

The conventional triaxial compression test results of lime mudstone shown in Fig. 1 are utilized to evaluate the rationality of the model proposed in this paper. First, the model parameters under such four different confining pressures as $\sigma_{3}=0 \mathrm{MPa}, \sigma_{3}=5 \mathrm{MPa}$, $\sigma_{3}=15 \mathrm{MPa}$ and $\sigma_{3}=20 \mathrm{MPa}$ are determined according to Eqs. (6), (15) and (16). For instance, when $\sigma_{3}=0 \mathrm{MPa}$, parameter $a$ can be determined as $a=15372 \mathrm{MPa}$ by substituting $\sigma_{3}=0 \mathrm{MPa}$ into Eq. (6); and parameter $n$ can be determined as $n=3.99$ by substituting $\sigma_{3}=0 \mathrm{MPa}$ into Eq. (15). Substituting $\sigma_{3}=0 \mathrm{MPa}$ and $n=3.99$ into Eq. (16), parameter $b$ can be determined as $b=6.60 \times 10^{8} \mathrm{MPa}^{-1}$. Then substituting $a=15372 \mathrm{MPa}, b=6.60 \times 10^{8} \mathrm{MPa}^{-1}$ and $n=3.99$ into Eq. (8), the axial stress-strain equation of lime mudstone under $\sigma_{3}=0 \mathrm{MPa}$ can be obtained and the predicted axial stress-strain curve can be further drawn. Under other confining pressures, the parameter determination method and procedure are similar. $\sigma_{3}=5 \mathrm{MPa}: a=16607 \mathrm{MPa}$, $b=1.98 \times 10^{6} \mathrm{MPa}^{-1}$ and $n=3.05 ; \sigma_{3}=15 \mathrm{MPa}: a=19077 \mathrm{MPa}, b=6.39 \times 10^{7} \mathrm{MPa}^{-1}$ and $n=3.98 ; \sigma_{3}=20 \mathrm{MPa}: a=20312 \mathrm{MPa}, b=5.13 \times 10^{8} \mathrm{MPa}^{-1}$ and $n=4.51$. Figure 7 presents the comparison of predicted curves and test data.

It can be seen from Fig. 7 that, for the complexity of rock mechanical properties, some errors are found to exist between predicted curves and test results. Figure 7a shows that the tested axial stress-strain curve of sample \#1 $\left(\sigma_{3}=0 \mathrm{MPa}\right)$ has a shorter elastic deformation stage but a longer plastic deformation stage before the peak point, and the 


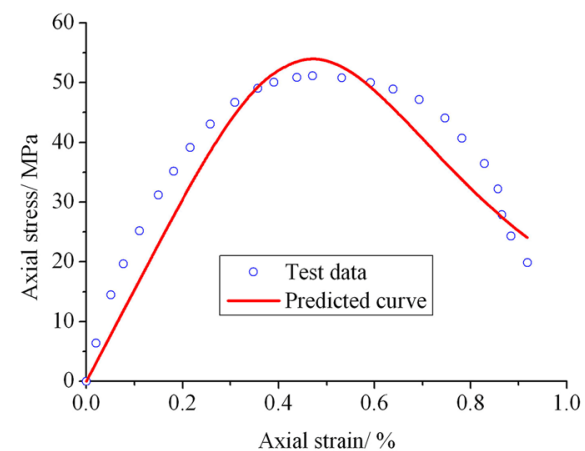

a

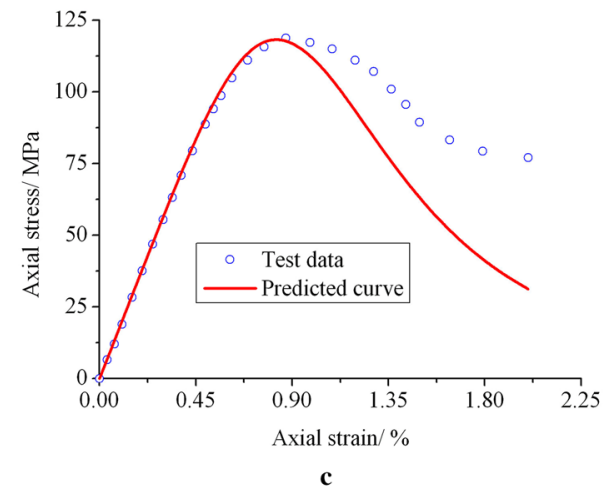

Fig. 7 Comparison of predicted curves and test data. a $\sigma_{3}=0 \mathrm{MPa}$. b $\sigma_{3}=5 \mathrm{MPa}$. $\sigma_{3}=15 \mathrm{MPa}$. $\sigma_{3}=20 \mathrm{MPa}$

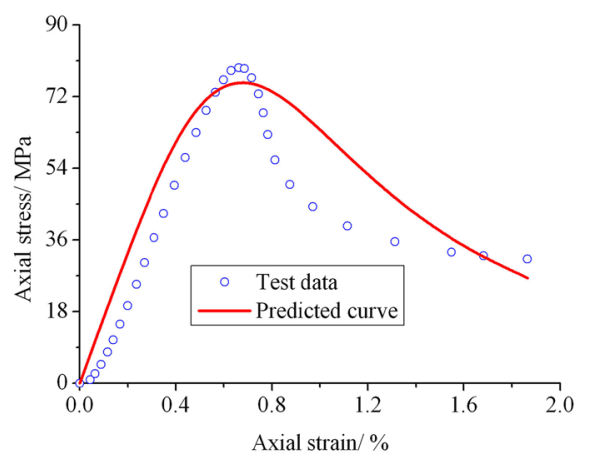

b

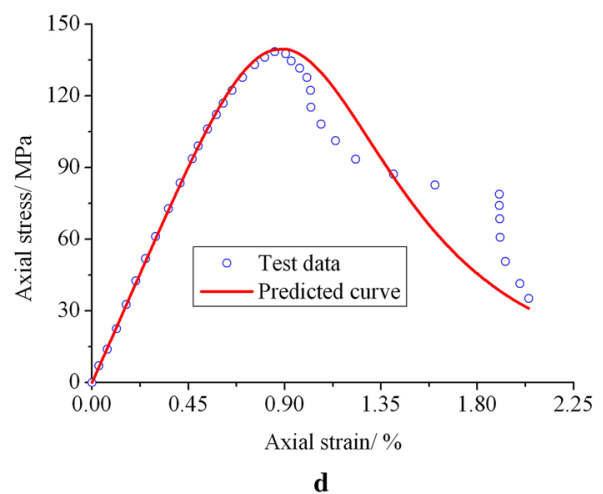

predicted curve from the model is relatively in poor agreement with the test data before the peak point. Figure $7 \mathrm{~b}$ indicates that the tested axial stress-strain curve of sample \#2 $\left(\sigma_{3}=5 \mathrm{MPa}\right)$ contains closure stage for voids and cracks, while the mechanical properties of rock in this stage are not considered in the model, so the predicted curve from the model is also relatively in poor agreement with the test data before the peak point. However, the comparison of predicted curves from the model and test data illustrates that, from the overall perspective, the new model proposed in this paper can preferably simulate the strain softening property of lime mudstone and the axial stress-strain response in rock failure process.

\section{Conclusions}

The conventional triaxial compression test results under different confining pressures $(0,5,15$ and $20 \mathrm{MPa})$ show that, in the range of $0 \mathrm{MPa} \leq \sigma_{3} \leq 20 \mathrm{MPa}$, the variations in axial peak stress and elastic modulus of lime mudstone with confining pressure can be described with linear functions; while the variation in axial peak strain of lime mudstone with confining pressure can be reflected with a power function. Moreover, the lime mudstone exhibits a horizontal tensile splitting failure mode under uniaxial compression and a typical shear failure mode under triaxial compression.

In order to precisely describe the axial stress-strain behavior in failure process of lime mudstone, a new constitutive model is proposed, with the model characteristics 
analyzed and the parameter determination method put forward. Then the rationality of the model is validated using the conventional triaxial compression test results of lime mudstone. The model parameters under different confining pressures are determined first, and then the predicted axial stress-strain curves are obtained by substituting the corresponding parameters into the constitutive equation. The comparison of predicted curves from the model and test data indicates that the new model can preferably simulate the strain softening property of lime mudstone and the axial stress-strain response in rock failure process.

\begin{abstract}
Abbreviations
$\sigma_{3}$ : confining pressure; $\sigma_{1}$ : axial peak stress; $\sigma_{0}$ : uniaxial compression strength of rock material; $k$ : material constant; $c$ : cohesion of rock material; $\varphi$ : internal friction angle of rock material; $\varepsilon_{1 c}:$ axial peak strain; $E$ : elastic modulus; $\sigma_{1}:$ axial stress; $\varepsilon_{1}$ : axial strain; $A$ : material parameter of Wang' model; $B$ : material parameter of Wang' model; $C$ : material parameter of Wang' model; $a$ : material parameter of the model proposed in this paper; $b$ : material parameter of the model proposed in this paper; $n$ : material parameter of the model proposed in this paper; $\sigma_{\infty}$ : residual strength; $E_{\mathrm{t}}$ : tangent elastic modulus; $E_{0}$ : initial tangent elastic modulus.
\end{abstract}

\title{
Authors' contributions
}

JW performed the experiments, established the constitutive model and wrote the manuscript. XL organized the research and participated in writing the manuscript. BZ discussed the constitutive model and revised the manuscript. ZS and JL discussed the experiments. All authors read and approved the final manuscript.

\section{Author details}

${ }^{1}$ School of Civil Engineering, Xi'an University of Architecture and Technology, Xi'an 710055, China. ${ }^{2}$ School of Civil Engineering, Chongqing University, Chongqing 400045, China. ${ }^{3}$ Department of Civil Engineering and Architecture, Chongqing University of Science and Technology, Chongqing 401331, China. ${ }^{4}$ School of Highway, Chang'an University, Xi'an 710064, China.

\section{Acknowledgements}

The present work is subsidized and supported by the National Natural Science Foundation of China (Nos. 51404184, 51578447, 41302223), the Natural Science Basic Research Program of Shaanxi Province (No. 2016JQ4009), the Specialized Scientific Research Program of Education Department of Shaanxi Provincial Government (No. 14JK1401) and the Science and Technology Foundation for Youth of Xi'an University of Architecture and Technology (No. RC1362). The financial supports are gratefully acknowledged by the authors!

\section{Competing interests}

The authors declare that they have no competing interests.

Received: 23 April 2016 Accepted: 11 September 2016

Published online: 21 September 2016

\section{References}

Alexeev AD, Revva VN, Bachurin LL, Prokhorov IY (2008) The effect of stress state factor on fracture of sandstones under true triaxial loading. Int J Fract 149:1-10

Asadollahi P, Invernizzi MCA, Addotto S, Tonon F (2010) Experimental validation of modified barton's model for rock fractures. Rock Mech Rock Eng 48:597-613

Chen J, Jiang DY, Ren S, Yang CH (2016a) Comparison of the characteristics of rock salt exposed to loading and unloading of confining pressures. Acta Geotech 11:221-230

Chen W, Konietzky H, Tan X, Frühwirt T (2016b) Pre-failure damage analysis for brittle rocks under triaxial compression. Comput Geotech 74:45-55

Deng J, Gu DS (2011) On a statistical damage constitutive model for rock materials. Comput Geotech 37:122-128

Duncan JM, Chang CY (1970) Nonlinear analysis of stress and strain in soils. J Soil Mech Found Div 96:1629-1653

Fairhurst CE, Hudson JA (1999) Draft ISRM suggested method for the complete stress-strain curve for the intact rock in uniaxial compression. Int J Rock Mech Min Sci 36:279-289

Hu DW, Zhang F, Shao JF (2014) Experimental study of poromechanical behavior of saturated claystone under triaxial compression. Acta Geotech 9:207-214

Huang D, Gu DM, Yang C, Huang RQ, Fu GY (2015) Investigation on mechanical behaviors of sandstone with two preexisting flaws under triaxial compression. Rock Mech Rock Eng 49:1-25

Indraratna B, Nimbalkar S, Coop M, Sloan SW (2014) A constitutive model for coal-fouled ballast capturing the effects of particle degradation. Comput Geotech 61:96-107

Kahraman S, Alber M (2008) Triaxial strength of a fault breccia of weak rocks in a strong matrix. Bull Eng Geol Environ $67: 435-441$

Lai JX, Mao S, Qiu JL, Fan HB, Zhang Q, Hu ZN, Chen JX (2016) Investigation progresses and applications of fractional derivative model in geotechnical engineering. Math Probl Eng. doi:10.1155/2016/9183296 
Lee DH, Juang CH, Chen JW, Lin HM, Shieh WH (1999) Stress paths and mechanical behavior of a sandstone in hollow cylinder tests. Int J Rock Mech Min Sci 36:857-870

Li HY, Shi GY (2016) A dynamic material model for rock materials under conditions of high confining pressures and high strain rates. Int J Impact Eng 89:38-48

Li DL, Liu XR, Liu XS (2015a) Experimental study on artificial cemented sand prepared with ordinary portland cement with different contents. Materials 8:3960-3974

Li HZ, Liao HJ, Xiong GD, Han B, Zhao GP (2015b) A three-dimensional statistical damage constitutive model for geomaterials. J Mech Sci Technol 29:71-77

Liang WG, Zhao YS, Xu SG, Dusseault MB (2011) Effect of strain rate on the mechanical properties of salt rock. Int J Rock Mech Min Sci 48:161-167

Liu HY, Zhang LM (2015) A damage constitutive model for rock mass with nonpersistently closed joints under uniaxial compression. Arab J Sci Eng 40:3107-3117

Nadimi S, Shahriar K (2014) Experimental creep tests and prediction of long-term creep behavior of grouting material. Arab J Geosci 7:3251-3257

Nadimi S, Shahriar K, Sharifzadeh M, Moarefvand P (2011) Triaxial creep tests and back analysis of time-dependent behavior of Siah Bisheh cavern by 3-dimensional Distinct Element Method. Tunn Undergr Space Technol 26:155-162

Siddiquee MSA, Islam MS, Tatsuoka F (2013) Development of a nonlinear model for soft rock and its applications. Geotech Geol Eng 31:627-645

Singh M, Samadhiya NK, Kumar A, Kumar V, Singh B (2015) A nonlinear criterion for triaxial strength of inherently anisotropic rocks. Rock Mech Rock Eng 48:1387-1405

Taheri A, Tani K (2013) Developing a damage model to simulate multiple-step loading triaxial compression tests in rocks. Geotech Geol Eng 31:541-5560

Unteregger D, Fuchs B, Hofstetter G (2015) A damage plasticity model for different types of intact rock. Int J Rock Mech Min Sci 80:402-441

Wang ZL, Li YC, Wang JG (2007) A damage-softening statistical constitutive model considering rock residual strength. Comput Geosci 33:1-9

Wang JB, Liu XR, Liu XJ, Huang M (2014) Creep properties and damage model for salt rock under low-frequency cyclic loading. Geomech Eng 7:569-587

Wang J, Xie LZ, Xie HP, Li CB (2015) Triaxial mechanical characteristics and constitutive model of oil sand in Fengcheng. J Sichuan Univ Eng Sci Ed 47:1-9

Xia M, Zhou KP (2010) Particle simulation of the failure process of brittle rock under triaxial compression. Int J Miner Metall Mater 17:507-513

Yang SQ, Su CD, Xu WY (2005) Experimental investigation on strength and deformation properties of marble under conventional triaxial compression. Rock Soil Mech 26:475-478

Yang YJ, Song Y, Chen SJ (2006) Test study of coal's strength and deformation characteristics under triaxial compression. J China Coal Soc 31:150-153

Yang SQ, Jing HW, Li YS, Han L (2011) Experimental investigation on mechanical behavior of coarse marble under six different loading paths. Exp Mech 51:315-334

Yang SQ, Jing HW, Wang SY (2012) Experimental investigation on the strength, deformability, failure behavior and acoustic emission locations of red sandstone under triaxial compression. Rock Mech Rock Eng 45:583-606

Yang SQ, Xu P, Ranjith PG, Chen GF, Jing HW (2015) Evaluation of creep mechanical behavior of deep-buried marble under triaxial cyclic loading. Arab J Geosci 8:1-16

You MQ (2003) Effect of confining pressure on the Young's modulus of rock specimen. Chin J Rock Mech Eng 22:53-60

Yu J, Chen X, Cai YY, Li H (2015) Triaxial test research on mechanical properties and permeability of sandstone with a single joint filled with gypsum. KSCE J Civ Eng. doi:10.1007/s12205-015-1663-7

Zhang P, Mishra B, Heasley KA (2015a) Experimental investigation on the influence of high pressure and high temperature on the mechanical properties of deep reservoir rocks. Rock Mech Rock Eng 48:2197-2211

Zhang Y, Shao JF, Xu WY, Zhao HB, Wang W (2015b) Experimental and numerical investigations on strength and deformation behavior of cataclastic sandstone. Rock Mech Rock Eng 48:1083-1096

\section{Submit your manuscript to a SpringerOpen ${ }^{\circ}$ journal and benefit from:}

- Convenient online submission

- Rigorous peer review

- Immediate publication on acceptance

Open access: articles freely available online

- High visibility within the field

- Retaining the copyright to your article

Submit your next manuscript at $>$ springeropen.com 